\title{
Microsurgical Anatomy of Safe Entry Zones on the Ventrolateral Brainstem: A Morphometric Study
}

\section{Ilke Bayzit Kocer}

Izmir Tinaztepe University

\section{Mine Oner Demiralin}

Izmir Bozyaka Training and Research Hospital

Mete Erturk

Ege University

\section{Dilek Arslan}

Izmir Tepecik Research and Training Hospital

Gulgun Sengul ( $\nabla$ gulgun.sengul@ege.edu.tr)

Ege Universitesi Tip Fakultesi https://orcid.org/0000-0002-5826-7379

\section{Research Article}

Keywords: Anatomical landmarks, Brainstem, Safe entry zone, Neurosurgery

Posted Date: June 8th, 2021

DOl: https://doi.org/10.21203/rs.3.rs-495493/v1

License: (c) (1) This work is licensed under a Creative Commons Attribution 4.0 International License.

Read Full License

Version of Record: A version of this preprint was published at Neurosurgical Review on September 21 st, 2021. See the published version at https://doi.org/10.1007/s10143-021-01644-9. 


\section{Abstract}

Surgery of the brainstem is challenging due to the complexity of the area with cranial nerve nuclei, reticular formation and ascending and descending fibers. Safe entry zones are required to reach the intrinsic lesions of the brainstem. The aim of this study was to provide detailed measurements for anatomical landmark zones of the ventrolateral surface of the human brainstem related to previously described safe entry zones. In this study, 53 complete and 34 midsagittal brainstems were measured using a stainless caliper with an accuracy of $0.01 \mathrm{~mm}$. The distance between the pontomesencephalic and bulbopontine sulci was measured as $26.94 \mathrm{~mm}$. Basilar sulcus-lateral side of pons (origin of the fibers of the trigeminal nerve) distance was $17.23 \mathrm{~mm}$, transverse length of the pyramid $5.42 \mathrm{~mm}$ and vertical length of the pyramid $21.36 \mathrm{~mm}$. Lateral mesencephalic sulcus was $12.73 \mathrm{~mm}$, distance of the lateral mesencephalic sulcus to the oculomotor nerve $13.85 \mathrm{~mm}$ and distance of trigeminal nerve to the upper tip of pyramid $17.58 \mathrm{~mm}$. The transverse length for the inferior olive at midpoint and vertical length were measured as $5.21 \mathrm{~mm}$ and $14.77 \mathrm{~mm}$, consequently. The thickness of the superior colliculus was $4.36 \mathrm{~mm}$, the inferior colliculus $5.06 \mathrm{~mm}$; length of the tectum was $14.5 \mathrm{~mm}$ and interpeduncular fossa $11.26 \mathrm{~mm}$. Profound anatomical knowledge and careful analysis of preoperative imaging are mandatory before surgery of the brainstem lesions. The results presented in this study will serve neurosurgeons operating in the brainstem region.

\section{Introduction}

The anatomical organization of the human brainstem is a complex amalgam of compact neuronal groups and dispersed cell areas with varying cytoarchitecture. Structures of the brainstem are very diverse with respect to functions they participate in, neuroactive elements they contain, and neural pathways they accommodate. Surgery of the brainstem is challenging due to the complexity of the area with numerous nuclei, the reticular formation, ascending and descending fibers. Safe entry zones are required to reach the intrinsic lesions of the brainstem. The study gives detailed measurements for anatomical landmark zones of the ventrolateral surface of the human brainstem such as the lateral mesencephalic sulcus, peritrigeminal area and inferior olive.

Infratentorial lesions such as neoplastic lesions, vascular malformations and abscesses are important in the brainstem region due to the presence of important structures in this restricted area. The majority of brainstem tumors are glial tumors $[8,18,28]$. Gliomas within the brainstem comprise $10-20 \%$ of pediatric central nervous system tumors [11, 19]; in adults, this ratio is about $5 \%$ [11]. Gliomas can be classified into four groups: focal, cervicomedullary, exophytic and diffuse $[11,12]$. Focal tumors are generally located in the midbrain, especially tectum, pons and bulbus [16]. If focal tumors are slow growing-lower grade, they can be operable $[12,16]$. Cervicomedullary gliomas arise from the lower bulbus or the upper cervical spinal cord [8]. These are operable, because they are slowly growing, low-grade gliomas [8, 1113]. Exophytic gliomas can be classified into dorsal exophytic gliomas and the ventrolateral exophytic gliomas [16]. Dorsal exophytic gliomas are more operable [11-13]; ventrolateral exophytic gliomas are more aggressive and higher grade, and not amenable to surgical resection $[11,13]$. Diffuse gliomas are 
not amenable to surgical resection because of location and infiltrative nature of tumors $[8,11-13,16]$. Other infratentorial lesions of brainstem are vascular malformations such as cavernomas. Cavernomas occur in the general population at an incidence of $0.4-0.9 \%[3,4,7]$. Cavernous malformations comprise $8-15 \%$ of all vascular malformations $[7,9]$. The prevalence of brainstem cavernomas are approximately $10-30 \%$ and they are usually located in pons $[4,7]$. Surgical resections can be applied taking the performance status of the patient and localization of cavernoma in consideration [3, 7]. The brainstem abscesses are rare infratentorial lesions. Despite representing less then $1 \%$ of all intracranial abscesses, they have high mortality $[21,27]$. Pons is the most common, midbrain is the second most likely site of the abscesses, and they are rarely seen in the bulbus [27]. Two different surgical approaches can be performed in brainstem abscesses; stereotactic biopsy $[2,10,21,24,27]$ and open craniotomy or microsurgery for therapeutic aspiration or abscess excision [24].

Surgery of the brainstem, despite advances in microsurgical techniques, intraoperative imaging and intraoperative electrophysiological monitoring, remains to be challenging. In-depth understanding the surface anatomy and inner architecture of the brainstem is critical for planning the appropriate approach, choosing the safe entry points, and avoiding complications during surgery. For lesions in the ventrolateral surface of the brainstem, particularly in the interpeduncular fossa and cerebral peduncles, a tyranssylvian approach with pterional or orbitozygomatic craniotomy is preferred. For the midbrain and upper one third of the pons, a subtemporal transtentorial approach can be used to reveal the oculomotor and trochlear nerves $[20,22]$ and the pontomesencephalic sulcus [14]. A pretemporal transcavernous approach is also possible $[6,22]$.

For lesions in the anterolateral surface of the medulla, a far lateral approach provides adequate exposure $[6,15,20]$. A suboccipital approach with laminectomy of the atlas exposes the olive, the lower cranial nerves and the $\mathrm{C} 1 \mathrm{spinal}$ nerve. This provides the neurosurgeon a surgical space of $13.5 \mathrm{~mm}$ [22]. Operating the lesions on the anterolateral surface of the pons at the level of the cerebellopontine angle and middle cerebellar peduncle is possible with a retrosigmoid approach following retromastoid craniotomy $[6,15]$. Presigmoid and transpetrous approaches are used to reach the peritrigeminal region that is surrounded by the pyramidal tract and the pontomedulary sulcus. Lesions located at the lateral midbrain surface can be approached through the lateral mesencephalic sulcus $[5,6,20]$.

In all these approaches for resection of intrinsic brainstem lesions, it is valuable to know the morphometry of the anatomical landmarks and their relationships to minimize morbidity. Therefore, the main objective of this study was to provide morphometric measurements of the surface structures of the ventrolateral brainstem to define anatomical safe entry zones for microsurgical resection of the midbrain, pons, and medulla lesions.

\section{Materials And Methods}

The present study was conducted on 53 complete and 34 midsagittal $10 \%$ formalin-fixed human brainstem specimens from the cadaver collection of Ege University, School of Medicine, Department of 
Anatomy, Izmir, Turkey, in accordance with the provisions of the Declaration of Helsinki 1995 (as revised in Edinburgh 2000). Thirteen parameters were measured for the right and left sides, using a stainless caliper with an accuracy of $0.01 \mathrm{~mm}$ using anatomic landmarks in the ventrolateral brainstem area.

- Pontomesencephalic sulcus - bulbopontine sulcus distance (M1): The distance between the superior midpoint to the inferior midpoint of the right part of pons was measured (Fig. 1).

- Basilar sulcus and the lateral side of pons distance (Origin of the fibers of CN V) (M2): The distance between the origin of the fibers of the right trigeminal nerve and the midline of the basilar sulcus was measured (Fig. 2).

- Transverse length of the pyramid (M3): the measurement was made from the midpoint of the lateral margin to the midpoint of the medial margin of the pyramid (Fig. 3).

- Vertical length of the pyramid (M4): the measurement was made from the superior midpoint to the inferior midpoint of the pyramid (Fig. 3).

- Lateral mesencephalic sulcus length (M5): The distance between the upper and lower tip of the mesencephalic sulcus was measured (Fig. 4).

- Lateral mesencephalic sulcus - oculomotor nerve distance (M6): The distance was measured from the upper tip of the lateral mesencephalic sulcus to the origin of the fibers of oculomotor nerve (Fig. $5)$.

- Trigeminal nerve - the upper tip of pyramid distance (M7): The measurement was from the origin of the fibers of the trigeminal nerve to the superior midpoint of the pyramid (Fig. 6).

- Transverse length of the inferior olive (M8): The distance between the midpoint of the lateral margin and the midpoint at the medial margin of inferior olive was measured (Fig. 7).

- Vertical length of the inferior olive (M9): The measurement was from the superior midpoint to the inferior midpoint of the inferior olive (Fig. 7).

- Thickness of the superior colliculus (M10): The distance was measured from the posterior margin of the superior colliculus to the posterior margin of the cerebral aqueduct (Fig. 8).

- Thickness of the inferior colliculus (M11): The distance was from the posterior margin of the inferior colliculus to the posterior margin of the cerebral aqueduct (Fig. 8).

- Length of the tectum (M12): The distance from the superior margin of the superior colliculus to the inferior margin of the inferior colliculus was measured (Fig. 8).

- Length of the interpeduncular fossa (M13): The distance between the rostral recess of the interpeduncular fossa and the triangular groove, bounded by left and right cerebral peduncles and the upper midpoint of the pons, was measured (Fig. 9).

\section{Results}

Both right and left sides were measured for all specimens. For all subjects, the mean diameters are shown in Table 1. Pontomesencephalic sulcus - bulbopontine sulcus distance (M1) was measured as $26.92 \mathrm{~mm}(26.98 \pm 2.29$ on the right side; $26.87 \pm 2.14$ on the left side) (Figure 1a), basilar sulcus - lateral 
side of pons (origin of the fibers of $C N V$ ) distance (M2) $17.23 \mathrm{~mm}(17.14 \pm 1.37$ on the right side; $17.32 \pm 1.32$ on the left side) (Figure 1b), transverse length of the pyramid (M3) $5.42 \mathrm{~mm}(5.38 \pm 0.61$ on the right side; $5.45 \pm 0.58$ on the left side) (Figure 2a), vertical length of the pyramid (M4) $21.36 \mathrm{~mm}$ (21.43 \pm 1.76 on the right side; $21.49 \pm 1.82$ on the left side) (Figure $2 \mathrm{~A}$ ), and the lateral mesencephalic sulcus (M5) length $12.73 \mathrm{~mm}$ (12.80 \pm 1.29 on the right side; $12.67 \pm 1.79$ on the left side) (Figure $2 \mathrm{~b}$ ). The distance of the lateral mesencephalic sulcus to the oculomotor nerve (M6) was measured $13.85 \mathrm{~mm}$ (13.99 \pm 2.24 on the right side; $13.71 \pm 1.84$ on the left side) (Figure $3 \mathrm{~A})$, distance of the trigeminal nerve to the upper tip of pyramid (M7) as $17.58 \mathrm{~mm}(17.36 \pm 1.93$ on the right side; $17.81 \pm 1.76$ on the left side) (Figure 3B), inferior olive transverse length (M8) as $5.21 \mathrm{~mm}(5.24 \pm 0.58$ on the right side; $5.18 \pm 0.49$ on the left side) (Figure 3c), inferior olive vertical length (M9) as $14.77 \mathrm{~mm}(14.79 \pm 1.26$ on the right side; $14.75 \pm 1.29$ on the left side) (Figure 3c), the thickness of superior (M10) and inferior (M11) colliculi as $4.36 \mathrm{~mm}$ ( $4.95 \pm 1.18$ on the right side; $3.76 \pm 0.53$ on the left side), and $5.06 \mathrm{~mm}(4.83 \pm 0.79$ on the right side; $5.30 \pm 1.66$ on the left side), respectively (Figure 4a). The length of the tectum (M12) was $14.50 \mathrm{~mm}$ (14.96 \pm 2.12 on the right side; $14.04 \pm 2.13$ on the left side) (Figure 4a), and the length of the interpeduncular fossa (M13) as $11.26 \mathrm{~mm}$ (11.40 \pm 1.06 on the right side; $11.13 \pm 1.03$ on the left side) (Figure 4b).

Table I: Measurements of the ventrolateral brainstem for both sides (R-L), and for the right (R) and left (L) sides separately. 


\begin{tabular}{|c|c|c|c|c|}
\hline & & Mean \pm SD & Min & Max \\
\hline \multirow[t]{3}{*}{ Pontomesencephalic sulcus - bulbopontine sulcus distance } & $\mathrm{R}$ & $26.98 \pm 2.29$ & 21.77 & 34.19 \\
\hline & L & $26.87 \pm 2.14$ & 21.94 & 32.63 \\
\hline & $\begin{array}{l}\text { R- } \\
\mathrm{L}\end{array}$ & $26.92 \pm 2.21$ & 21.77 & 34.19 \\
\hline \multirow[t]{3}{*}{ Basilar sulcus - lateral side of pons distance } & $\mathrm{R}$ & $17.14 \pm 1.37$ & 14.36 & 22.12 \\
\hline & $\mathrm{L}$ & $17.32 \pm 1.32$ & 14.15 & 20.07 \\
\hline & $\begin{array}{l}\text { R- } \\
\mathrm{L}\end{array}$ & $17.23 \pm 1.34$ & 14.15 & 22.12 \\
\hline \multirow[t]{3}{*}{ Transverse length of the pyramid } & $\mathrm{R}$ & $5.38 \pm 0.61$ & 3.82 & 6.86 \\
\hline & $\mathrm{L}$ & $5.45 \pm 0.58$ & 4.44 & 6.78 \\
\hline & $\begin{array}{l}\mathrm{R}- \\
\mathrm{L}\end{array}$ & $5.42 \pm 0.60$ & 3.82 & 6.86 \\
\hline \multirow{3}{*}{ Vertical length of the pyramid } & $\mathrm{R}$ & $21.43 \pm 1.76$ & 17.48 & 23.55 \\
\hline & L & $21.49 \pm 1.82$ & 17.31 & 24.18 \\
\hline & $\begin{array}{l}\text { R- } \\
\mathrm{L}\end{array}$ & $21.36 \pm 1.76$ & 17.31 & 24.18 \\
\hline \multirow[t]{3}{*}{ Length of the lateral mesencephalic sulcus } & $\mathrm{R}$ & $12.80 \pm 1.29$ & 10.40 & 14.35 \\
\hline & L & $12.67 \pm 1.79$ & 9.91 & 15.75 \\
\hline & $\begin{array}{l}\text { R- } \\
\mathrm{L}\end{array}$ & $12.73 \pm 1.51$ & 9.91 & 15.75 \\
\hline \multirow{3}{*}{$\begin{array}{l}\text { Lateral mesencephalic sulcus - origin of the oculomotor nerve } \\
\text { distance }\end{array}$} & $\mathrm{R}$ & $13.99 \pm 2.24$ & 11.54 & 15.95 \\
\hline & L & $13.71 \pm 1.84$ & 11.72 & 15.35 \\
\hline & $\begin{array}{l}\text { R- } \\
\mathrm{L}\end{array}$ & $13.85 \pm 1.84$ & 11.54 & 15.95 \\
\hline \multirow[t]{3}{*}{ Origin of the trigeminal nerve - upper tip of pyramid distance } & $\mathrm{R}$ & $17.36 \pm 1.93$ & 13.60 & 22.18 \\
\hline & $\mathrm{L}$ & $17.81 \pm 1.76$ & 14.54 & 21.68 \\
\hline & $\begin{array}{l}\text { R- } \\
\mathrm{L}\end{array}$ & $17.58 \pm 1.85$ & 13.60 & 22.18 \\
\hline \multirow[t]{3}{*}{ Transverse length of the inferior olive } & $\mathrm{R}$ & $5.24 \pm 0.58$ & 3.96 & 6.67 \\
\hline & L & $5.18 \pm 0.49$ & 4.19 & 6.59 \\
\hline & $\begin{array}{l}\mathrm{R}- \\
\mathrm{L}\end{array}$ & $5.21 \pm 0.53$ & 3.96 & 6.67 \\
\hline
\end{tabular}




\begin{tabular}{|c|c|c|c|c|}
\hline \multirow[t]{3}{*}{ Vertical length of the inferior olive } & $\mathrm{R}$ & $14.79 \pm 1.26$ & 10.91 & 17.82 \\
\hline & $\mathrm{L}$ & $14.75 \pm 1.29$ & 11.09 & 17.03 \\
\hline & $\begin{array}{l}\text { R- } \\
\text { L }\end{array}$ & $14.77 \pm 1.27$ & 10.91 & 17.82 \\
\hline \multirow[t]{3}{*}{ Superior colliculus thickness } & $\mathrm{R}$ & $4.95 \pm 1.18$ & 3.11 & 7.14 \\
\hline & $\mathrm{L}$ & $3.76 \pm 0.53$ & 3.39 & 4.14 \\
\hline & $\begin{array}{l}\text { R- } \\
\text { L }\end{array}$ & $4.36 \pm 1.17$ & 3.11 & 7.14 \\
\hline \multirow[t]{3}{*}{ Inferior colliculus thickness } & $\mathrm{R}$ & $4.83 \pm 0.79$ & 3.40 & 5.95 \\
\hline & $\mathrm{L}$ & $5.30 \pm 1.66$ & 4.13 & 6.48 \\
\hline & $\begin{array}{l}\text { R- } \\
\text { L }\end{array}$ & $5.06 \pm 0.89$ & 3.40 & 6.48 \\
\hline \multirow[t]{3}{*}{ Tectum length } & $\mathrm{R}$ & $14.96 \pm 2.12$ & 12.90 & 20.79 \\
\hline & $\mathrm{L}$ & $14.04 \pm 2.13$ & 11.47 & 15.84 \\
\hline & $\begin{array}{l}\text { R- } \\
\text { L }\end{array}$ & $14.50 \pm 2.09$ & 11.47 & 20.79 \\
\hline \multirow[t]{3}{*}{ Length of the interpeduncular fossa } & $\mathrm{R}$ & $11.40 \pm 1.06$ & 9.67 & 13.13 \\
\hline & $\mathrm{L}$ & $11.13 \pm 1.03$ & 9.94 & 11.79 \\
\hline & $\begin{array}{l}\text { R- } \\
\text { L }\end{array}$ & $11.26 \pm 1.01$ & 9.67 & 13.13 \\
\hline
\end{tabular}

\section{Discussion}

The main objective in this study was to measure the distances between the anatomical landmarks of the human brainstem for defining the safe entry zones on the ventrolateral surface of the human brainstem. As discussed here, there are a number of studies on the morphometry of the ventrolateral surface of the human brainstem. In these different measurement parameters, different techniques and study populations are used.

The pontomesencephalic and bulbopontine sulci distance was measured by Kazda and Putz [17] as 28.6 mm (min. 22 - max. $33 \mathrm{~mm}$ ). In this study, we measured the average pontomesencephalic sulcus bulbopontine sulcus diameter $26.92 \mathrm{~mm}$ (min. 21.77 - max. 34.19 on the right side; min. 21.94 - max. $32.63 \mathrm{~mm}$ on the left side). For the basilar sulcus - lateral side of pons distance, Kazda and Putz [17] measured the average length as $18.6 \mathrm{~mm}$ on the right side and $19.7 \mathrm{~mm}$ on the left side. In the present study, we measured the basilar sulcus - lateral side of pons distance $17.14 \mathrm{~mm}$ ( $\mathrm{min} .14 .36$ - max. 22.12 $\mathrm{mm}$ ) on the right side, $17.32 \mathrm{~mm}$ ( $\mathrm{min} .14 .15$ - $\max .20 .07 \mathrm{~mm}$ ) on the left side, and $17.23 \mathrm{~mm}$ for both sides. 
Akar et al. [1] measured the transverse length of the pyramid as $6.1 \mathrm{~mm}$ ( $\min .5$ - $\mathrm{max} .7 \mathrm{~mm}$ on the right side; min. 4 - max. $8 \mathrm{~mm}$ on the left side. For the same parameter, Kazda and Putz [17] measured the length as $5.5 \mathrm{~mm}$ (min. 4 - max. $7 \mathrm{~mm}$ ). In the present study, we measured the transverse length of the pyramid as $5.38 \mathrm{~mm}$ ( $\min .3 .82$ - $\max .86 \mathrm{~mm}$ ) on the right side and $5.45 \mathrm{~mm}$ ( $\min .4 .44$ - $\max .6 .78 \mathrm{~mm}$ ) on the left side. When both the right and lefts sides were considered, the mean pyramid transverse length was $5.42 \mathrm{~mm}$.

The vertical length of pyramid was measured as $19.7 \mathrm{~mm}$ ( $\min .16$ - $\max .22 \mathrm{~mm}$ ) on the right side; 18.5 $\mathrm{mm}$ (min. 13 - max. $21 \mathrm{~mm}$ ) on the left side in study of Akar et al. [1]. In the present study, we measured the vertical length as $21.43 \mathrm{~mm}$ ( $\mathrm{min} .17 .48$ - max. $23.55 \mathrm{~mm}$ ) on the right side, and $21.29 \mathrm{~mm}$ (min. 17.31 - max. $24.18 \mathrm{~mm}$ ) on the left side; the mean diameter was $21.36 \mathrm{~mm}$.

The safe entry zone for the lateral mesencephalic sulcus is between the substantia nigra anterolaterally and the medial lemniscus posteriorly [6]. Recalde et al. [25] measured lateral mesencephalic sulcus length as $9.6 \mathrm{~mm}$ ( $\mathrm{min} .7 .4$ - max. $13.3 \mathrm{~mm}$ ). In the present study, we measured this length as $12.8 \mathrm{~mm}$ ( $\mathrm{min}$. 10.4 - max. $14.35 \mathrm{~mm}$ ) on the right side, and $12.67 \mathrm{~mm}$ ( $\min .9 .91$ - max. $15.75 \mathrm{~mm}$ ) on the left side. Yang et al. [29] reported the average length of the safe entry zone, extending from the medial geniculate body to the pontomesencephalic sulcus, as $9.6 \mathrm{~mm}$ ( $\min .7 .4$ - max. $13.3 \mathrm{~mm}$ ), with an average depth of $8 \mathrm{~mm}$ (min. 4.9 - max. $11.7 \mathrm{~mm}$ ).

The anterolateral surface of the pons is considered a safe zone for entering the brainstem [26]. Recalde et al. [25] also cut the descending fibers at the level of the trigeminal nerve, resected rostrally, and observed the substantia nigra as well as the intraneural projection of the oculomotor nerve. They measured the distance between the oculomotor nerve where it penetrated the substantia nigra and the lateral mesencephalic sulcus as $8.02 \mathrm{~mm}(\mathrm{~min} .4 .9$ - max. $11.7 \mathrm{~mm}$ ). In this study, we measured the distance between the oculomotor nerve where it emerged from the anterior surface of the brainstem and the lateral mesencephalic sulcus. This length was $13.99 \mathrm{~mm}$ ( $\min .11 .54$ - max. $15.95 \mathrm{~mm}$ ) on the right side, and $13.71 \mathrm{~mm}$ (min. 11.72 - max. $15.35 \mathrm{~mm}$ ) on the left side; $13.85 \mathrm{~mm}$ for both sides.

Recalde et al. [25] also measured the distance between the trigeminal nerve and pyramidal fibers as 4.64 $\mathrm{mm}$ ( $\min .3 .1$ - max. $5.6 \mathrm{~mm}$ ). In the present study, we measured the distance between the trigeminal nerve where it emerged from ventrolateral surface of brainstem and the upper tip of pyramid as 17.58 $\mathrm{mm} ; 17.36 \mathrm{~mm}$ ( $\min .13 .6$ - $\max .22 .18 \mathrm{~mm}$ ) on the right side, and $17.81 \mathrm{~mm}(\mathrm{~min} .14 .54$ - $\max .21 .68$ $\mathrm{mm}$ ) on the left side.

For the transverse length of the inferior olive, Akar et al. [1] measured the superior and the inferior portions of the inferior olive. However, their measurements for the inferior olive were not at the midpoint line, but more lateral. We measured the transverse length of the inferior olive at the midpoint line as $5.21 \mathrm{~mm} ; 5.24$ $\mathrm{mm}(\min .3 .96$ - $\max .6 .77 \mathrm{~mm}$ ) on the right side and $5.18 \mathrm{~mm}(\min .4 .19$ - $\max .6 .59 \mathrm{~mm}$ ) on the left side. Akar et al. [1] measured the vertical length of inferior olive as $11.7 \mathrm{~mm}(\mathrm{~min} .9$ - $\max .15 \mathrm{~mm})$ on the right side, and $10.8 \mathrm{~mm}$ ( $\mathrm{min} .10$ - max. $15 \mathrm{~mm}$ ) on the left side. Our measurements for this length were 
higher, $14.79 \mathrm{~mm}$ (min. 10.91 - max. $17.82 \mathrm{~mm}$ ) for the right side, $14.75 \mathrm{~mm}$ (min. 11.09 - $\max .17 .03$ $\mathrm{mm}$ ) for the left side.

Sabanciogullari et al. [26] measured the tectum structures on the ventrolateral brainstem on MR images of patients, unlike our measurements on $10 \%$ formalin-fixed cadavers. They measured the length as 3.92 $\mathrm{mm}$ (min. 2.2- $\max .6 .1 \mathrm{~mm}$ ) and $4.79 \mathrm{~mm}$ (min. 3 - max. $6.3 \mathrm{~mm}$ ) for the superior and inferior colliculi, respectively. In the present study on $10 \%$ formalin-fixed cadavers, the length was $4.95 \mathrm{~mm}$ (min. 3.11 max. $7.14 \mathrm{~mm}$ ) on right side, and $3.76 \mathrm{~mm}$ ( $\mathrm{min}$. 3.39 - max. $4.14 \mathrm{~mm}$ ) on the left side; and $5.06 \mathrm{~mm} ; 4.83$ $\mathrm{mm}$ (min. 3.4 - max. $5.95 \mathrm{~mm}$ ) on the right side, $5.3 \mathrm{~mm}$ ( $\min .4 .13$ - max. $6.48 \mathrm{~mm}$ ) on the left side, for the superior and inferior colliculi, respectively. The length of tectum was also measured by

Sabanciogullari et al. [26] as $13.57 \mathrm{~mm}$ (min. 10.3 - max. $16 \mathrm{~mm}$ ). Our results were $14.96 \mathrm{~mm}$ (min. 12.9 $\max .20 .79 \mathrm{~mm}$ ) on the right side, and $14.04 \mathrm{~mm}$ (min. 11.47 - max. $15.84 \mathrm{~mm}$ ) on the left side. When both left and right sides were considered, our mean tectum length was $14.5 \mathrm{~mm}$.

The interpeduncular fossa length was measured as $11.72 \mathrm{~mm}$ ( $\mathrm{min} .7$ - max. $20 \mathrm{~mm}$ ) on unfixed human brain specimens by Pedroza et al. [23]. In the present study, the interpeduncular fossa length was measured as $11.4 \mathrm{~mm}$ ( $\mathrm{min} .9 .67$ - max. $13.13 \mathrm{~mm}$ ) of the right side, and $11.13 \mathrm{~mm}$ (min. 9.94 - max. $11.79 \mathrm{~mm}$ ) on the left side. When both left and right sides were considered, the mean interpeduncular fossa length was $11.26 \mathrm{~mm}$.

In conclusion, this study provides the morphometry of the ventrolateral brainstem structures as a reference for surgical approaches to intrinsic brainstem lesions. Thorough anatomical knowledge and careful analysis of preoperative imaging are essential before surgery of brainstem lesions such as gliomas, cavernomas or abscesses. Presenting many measurement parameters related to safe entry zones to the brainstem, we suggest the findings of this study may be of significant assistance to neurosurgeons operating on this challenging region.

\section{Declarations}

\section{Acknowledgements}

The authors sincerely thank those who donated their bodies to science so that anatomical research could be performed.

\section{Funding}

No funding was received for this study.

\section{Conflicts of interest disclosure}

The authors report no conflicts of interest concerning the materials or methods used in this study or the findings specified in this paper. 
Availability of data and material (data transparency)

All data and materials support published claims and comply with field standards.

Code availability (software application or custom code)

Not applicable

\section{Ethics approval}

This is a cadaveric study not involving human participants and therefore does require ethical approval.

\section{Consent to participate}

Not applicable

\section{Consent for publication}

This is a cadaveric study not involving human participants or patient information and therefore does not require informed consent for publication.

\section{Authors' contributions}

Conception and design: Gulgun Sengul, Mete Erturk. Acquisition of data: Gulgun Sengul, Mete Erturk, Illke Bayzit Kocer, Mine Oner Demiralin. Analysis and interpretation of data: Gulgun Sengul, Mete Erturk, Illke Bayzit Kocer, Mine Oner Demiralin, Dilek Arslan. Drafting the article: Gulgun Sengul, Mete Erturk, Illke Bayzit Kocer, Dilek Arslan. Reviewed submitted version of manuscript: All authors.

\section{References}

1. Akar ZC, Dujovny M, Gomez-Tortosa E, Slavin KV, Ausman JI (1995) Microvascular anatomy of the anterior surface of the medulla oblongata and olive. J Neurosurg 82:97-105. doi: 10.1080/01616412.1994.11740221

2. Alvis Miranda H, Castellar-Leones SM, Elzain MA, Moscote-Salazar LR (2013) Brain abscess: Current management. J Neurosci Rural Pract 4:S67-S81. doi: 10.4103/0976-3147.116472

3. Asaad WF, Walcott BP, Nahed BV, Ogilvy CS (2010) Operative management of brainstem cavernous malformations. Neurosurg Focus 29:1-10. doi: 10.3171/2010.6.FOCUS10134

4. Bozinov O, Hatano T, Sarnthein J, Burkhardt JK, Bertalanffy H (2010) Current clinical management of brainstem cavernomas. Swiss Medical Weekly 140:w13120. doi: 10.4414/smw.2010.13120

5. Cavalcanti DD, Morais BA, Figueiredo EG, Spetzler RF, Preul MC (2019) Surgical approaches for the lateral mesencephalic sulcus. J Neurosurg 132:1653-1658. doi: 10.3171/2019.1.JNS182036

6. Cavalcanti DD, Preul MC, Kalani MY, Spetzler RF (2016) Microsurgical anatomy of safe entry zones to the brainstem. J Neurosurg 124:1359-1376. doi: 10.3171/2015.4.JNS141945 
7. De Aguiar PHP, Zicarelli CAM, Isolan G, Antunes A, Aires R, Georgeto SM, Tahara A, Haddad F (2012) Brainstem cavernomas: A surgical challenge. Einstein (Sao Paulo) 10:67-73. doi: 10.1590/s167945082012000100014

8. Freeman CR, Farmer JP (1998) Pediatric brain stem gliomas: a review. Int J Radiat Phys 40:265271. doi: 10.1016/s0360-3016(97)00572-5

9. Giulioni M, Acciarri N, Padovani R, Frank F, Galassi E, Gaist G (1994) Surgical management of cavernous angiomas in children. Surg Neurol 42:194-199. doi: 10.1016/0090-3019(94)90262-3

10. Gonçalves-Ferreira AJ, Herculano-Carvalho M, Pimentel J (2003) Stereotactic biopsies of focal brainstem lesions. Surg Neurol 60:311-20. doi: 10.1016/s0090-3019(03)00379-3

11. Hansen EK, Roach III M (2018) Handbook of evidence-based radiation oncology. 3rd edn. Springer, New York

12. Jallo Gl, Biser-Rohrbaugh A, Freed D (2004) Brainstem gliomas. Childs Nerv Syst 20:143-153. doi: 10.1007/s00381-003-0870-6

13. Jallo GI, Freed D, Roonprapunt C, Epstein F (2003) Current management of brainstem gliomas. Annals of Neurosurgery 3:1-17.

14. Jittapiromsak P, Little AS, Deshmukh P, Nakaji P, Spetzler RF, Preul MC (2008) Comparative analysis of the retrosigmoid and lateral supracerebellar infratentorial approaches along the lateral surface of the pontomesencephalic junction: a different perspective. Neurosurgery 62:0NS279-287. doi: 10.1227/01.neu.0000326008.69068.9a.

15. Kalani MY, Yagmurlu K, Martirosyan NL, Cavalcanti DD, Spetzler RF (2016) Approach selection for intrinsic brainstem pathologies J Neurosurg 125:1596-1607. doi: 10.3171/2016.6.JNS161043

16. Kan P, Kestle JRW (2008) Brainstem tumors. In: Bernstein M and Berger MS (eds) Neurooncology, the essentials, 2nd edn. Thieme, New York, 2008, pp 272-286

17. Kazda S, Putz R (1981) Die verhältnisse des nervus trigeminus an seiner austrittstelle aus dem hirnstamm [The connections of the trigeminal nerve at its emergence from the brain stem]. Morphol Med 1:25-30

18. Laigle-Donadey F, Doz F, Delattre JY (2008) Brainstem gliomas in children and adults. Curr Opin Oncol 20:662-667. doi: 10.1097/CCO.0b013e32831186e0

19. Mehta VS, Chandra PS, Singh PK, Garg A, Rath GK (2009) Surgical considerations for 'intrinsic' brainstem gliomas: Proposal of a modification in classification. Neurology India 57:274-281. doi: 10.4103/0028-3886.53272

20. Meybodi AT, Lawton MT, Mokhtari P, Kola O, El-Sayed IH, Benet A (2017) Exposure of the external carotid artery through the posterior triangle of the neck: a novel approach to facilitate bypass procedures to the posterior cerebral circulation. Oper Neurosurg (Hagerstown) 13:374-381. doi: 10.1093/ons/opw024

21. Nakajima H, Iwai Y, Yamanaka K, Kishi H (1999) Successful treatment of brainstem abscess with stereotactic aspiration. Surg Neurol 52:445-448. doi: 10.1016/s0090-3019(99)00146-9. 
22. Párraga RG, Possatti LL, Alves RV, Ribas GC, Türe U, de Oliveira EJ (2016) Microsurgical anatomy and internal architecture of the brainstemin 3D images: surgical considerations. J Neurosurg 124:1377-1395. doi: 10.3171/2015.4.JNS132778

23. Pedroza A, Dujovny M, Ausman JI, Diaz FG, Cabezudo Artero J, Berman SK, Mirchandani HG, Umansky F (1986) Microvascular anatomy of the interpeduncular fossa. J Neurosurg 64:484-493. doi: $10.3171 /$ jns. 1986.64 .3 .0484

24. Ramalho J, Castillo M (2008) Case of the season: brainstem abscess. Semin Roentgenol 43:168170. doi: 10.1053 j.ro.2008.03.001

25. Recalde RJ, Figueiredo EG, Oliveira E (2008) Microsurgical anatomy of the safe entry zones on the anterolateral brainstem related to surgical approaches to cavernous malformations. Neurosurgery 62:9-15. doi: 10.1227/01.neu.0000317368.69523.40

26. Sabanciogullari V, Salk I, Balaban H, Oztoprak I, Kelkit S, Cimen M (2013) Magnetic resonance imaging mesencephalic tectum dimensions according to age and gender. Neurosciences 18:33-39.

27. Suzer T, Coskun E, Cirak B, Yagci B, Tahta K (2005) Brain stem abscesses in childhood. Childs Nerv Syst 21:27-31. doi: 10.1007/s00381-004-1024-1

28. Walker DA, Punt JA, Sokal M (1999) Clinical management of brain stem glioma. Arch Dis Child 80:558-564. doi: 10.1136/adc.80.6.558

29. Yang Y, van Niftrik B, Ma X, Velz J, Wang S, Regli L, Bozinov O (2019) Analysis of safe entry zones into the brainstem. Neurosurg Rev 42:721-729. doi: 10.1007/s10143-019-01081-9

\section{Figures}



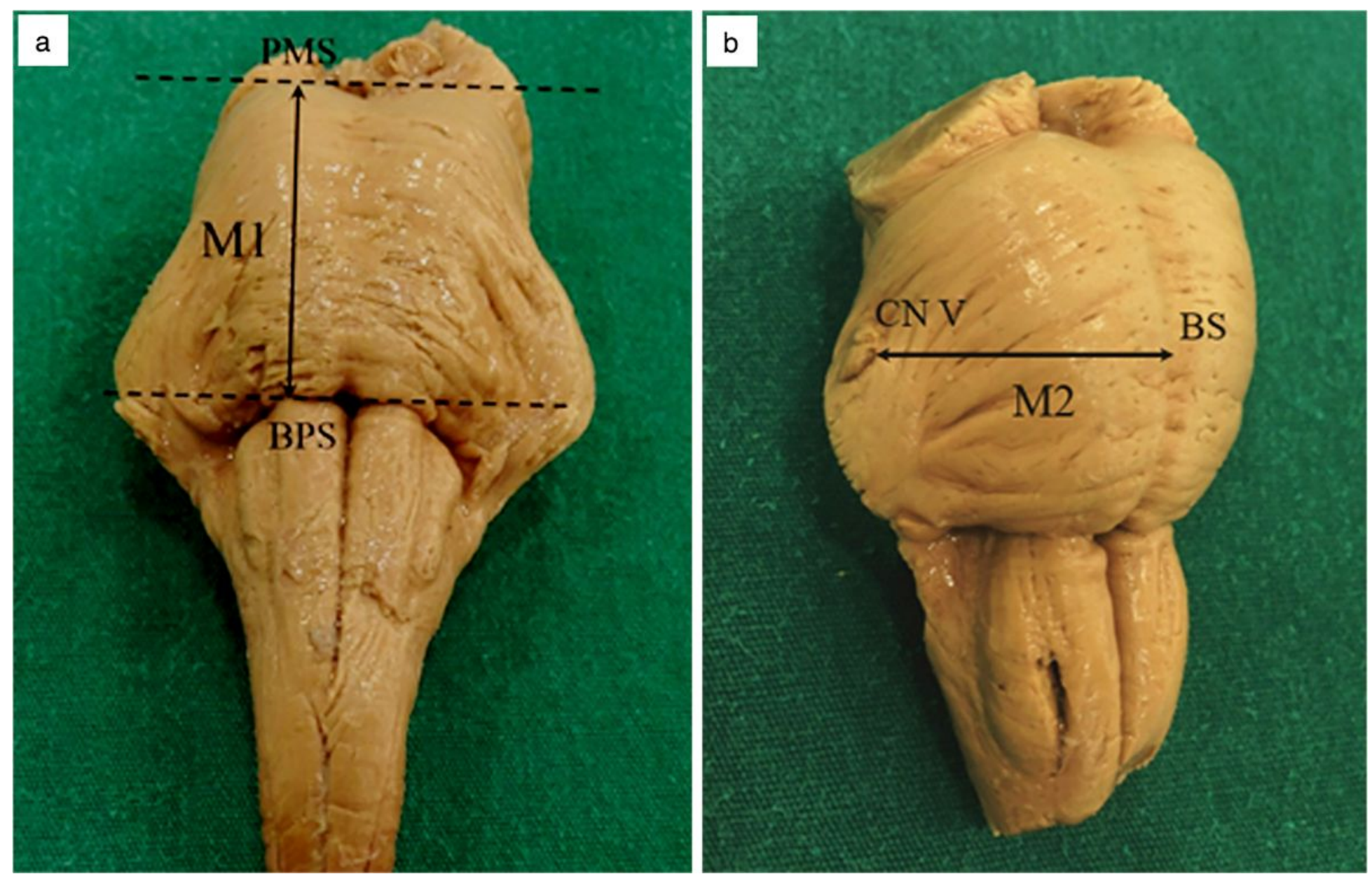

Figure 1

a The distance between the pontomesencephalic and bulbopontine sulci (M1). b The distance between basilar sulcus and the origin of trigeminal nerve (CN V) (M2). BS: basilar sulcus, BPS: bulbopontine sulcus, CN V: trigeminal nerve, PMS: pontomesencephalic sulcus. 


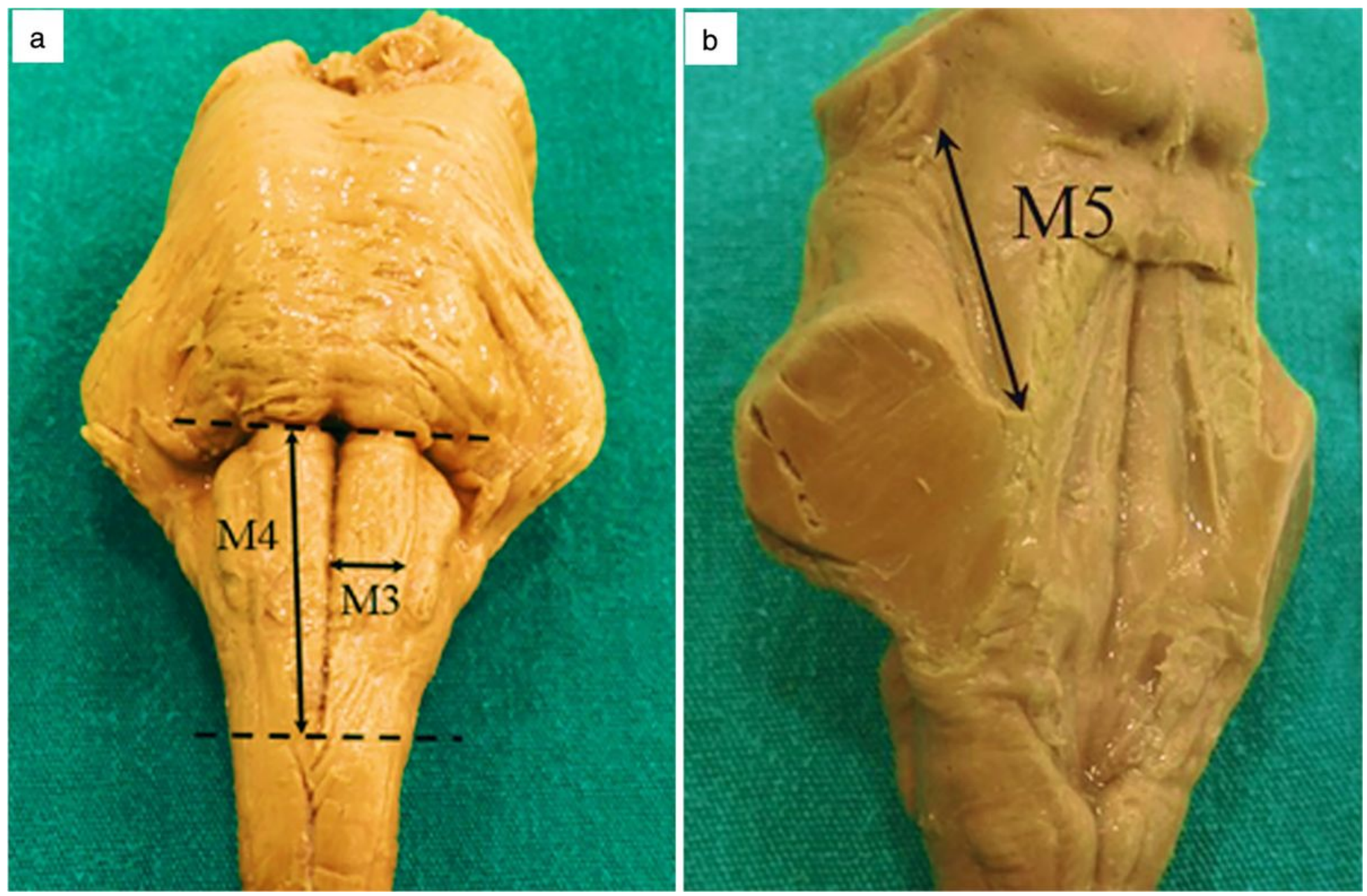

Figure 2

a Vertical and transverse lengths of pyramid (M3 and M4). DP: decussation of pyramids. $b$ Length of the lateral mesencephalic sulcus (M5).
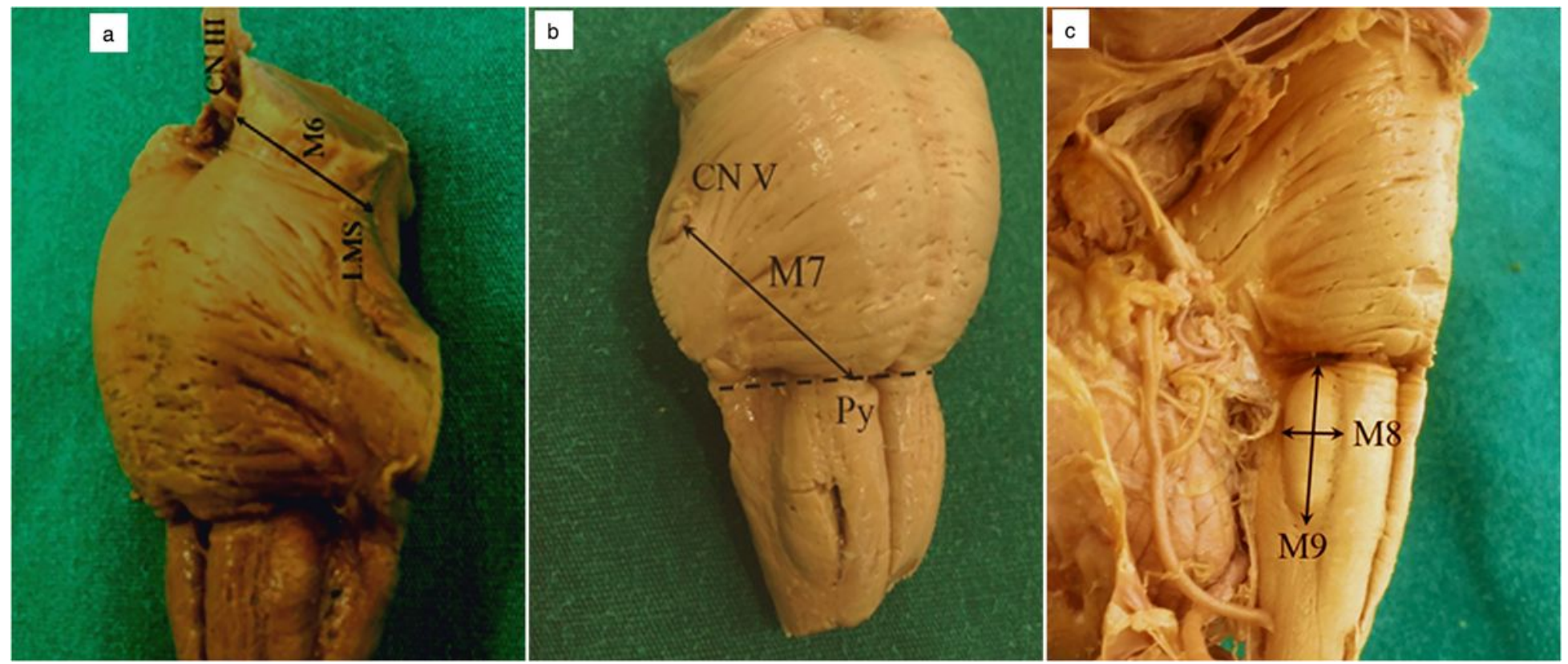

Figure 3 
a The distance between the lateral mesencephalic sulcus and the oculomotor nerve (M6). b The distance between the trigeminal nerve and the upper tip of the pyramid (M7). CN III: oculomotor nerve, CN V: trigeminal nerve, LMS: lateral mesencephalic sulcus, Py: pyramid. c Transverse and vertical lengths of the inferior olive (M8 - M9).
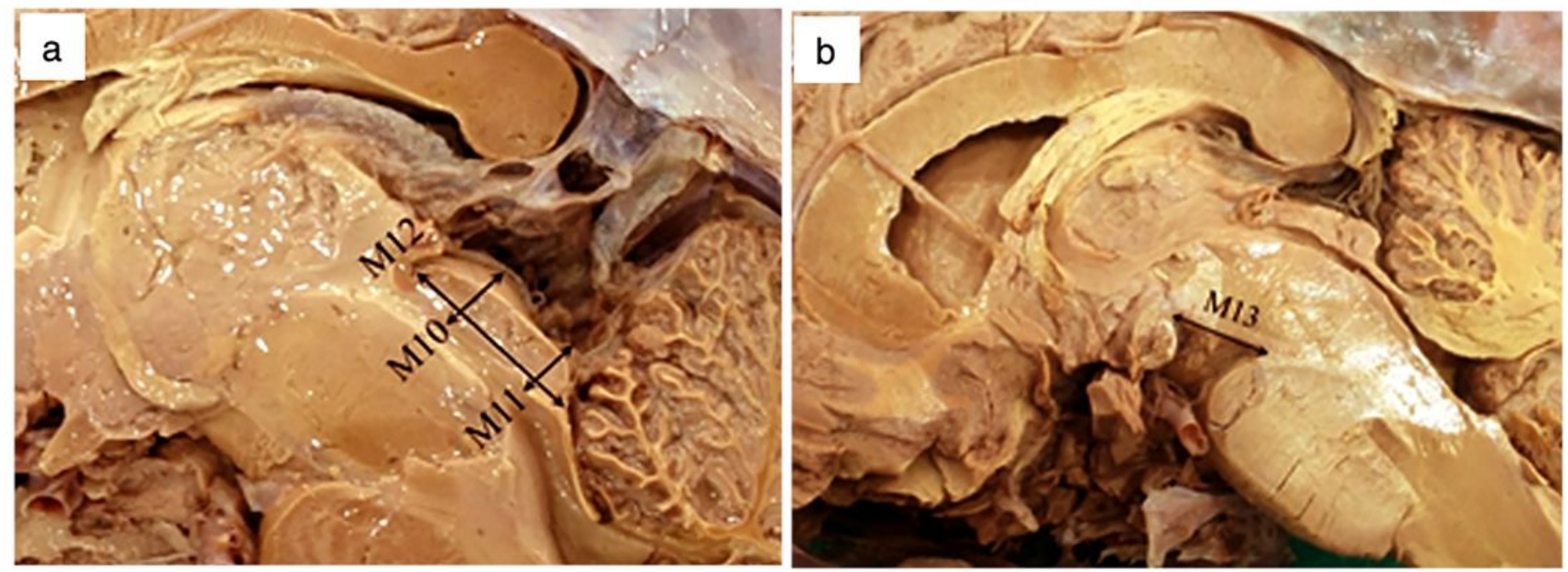

Figure 4

a The thickness of superior and inferior colliculi (M10 - M11) and tectum length (M12). b Length of the interpeduncular fossa (M13). 